\title{
SCIENTIFIC REPORTS

\section{OPEN Sarcodia suieae acetyl-xylogalactan regulate RAW 264.7 macrophage NF-kappa B activation and IL-1 beta cytokine production in macrophage polarization}

\begin{abstract}
Tsung-Meng Wu ${ }^{1}$, Fan-Hua Nan ${ }^{2}$, Kuan-Chu Chen ${ }^{1} \&$ Yu-Sheng Wu ${ }^{1 *}$
In this study, the effects of acetyl-xylogalactan extracted from Sarcodia suieae on RAW 264.7 macrophage polarisation were evaluated. This extracted acetyl-xylogalactan had a monosaccharide composition of $91 \%$ galactose and $9 \%$ xylose, with polysaccharide and acetyl contents of $80.6 \%$ and $19.3 \%$, respectively. MALDI-TOF mass spectrometry and NMR spectroscopy revealed the molecular weight of the acetyl-xylogalactan to be $88.5 \mathrm{kDa}$. After acetyl-xylogalactan treatment, RAW 264.7 macrophage polarisation was noted, along with enhanced phagocytic ability. Furthermore, the Cell Counting Kit-8 (CCK-8) assay was performed and the results demonstrated non-significant alteration in lactate dehydrogenase levels in the treated cells. Next, interleukin (IL) 1 $\beta$, TNF, and Malt-1 expression in RAW 264.7 macrophages treated with the $S$. suieae acetyl-xylogalactan was investigated through real-time quantitative polymerase chain reaction, and the results demonstrated that $S$. suieae acetylxylogalactan induced IL-1 $\beta$ and Malt-1 expression. RNA sequencing analysis results indicated the $S$. suieae acetyl-xylogalactan positively regulated cytokine production and secretion, protein secretion, and response to IL-1 activation, based on the observed GO terms. The predicted target genes in the GO enrichment analysis were found to upregulate NF- $\kappa B$ signalling and $M 0$ to $M 1$ macrophage conversion through the observed cytokine production. Thus, acetyl-xylogalactan can positively regulate RAW
\end{abstract} 264.7 macrophage polarisation.

Innate immune cells, such as macrophages, dendritic cells, and other nonimmune cells, are involved in the response to invading pathogens ${ }^{1}$. The administration of algal polysaccharides can enhance tumour-suppressing and antiallergic abilities by modulating the host immune system ${ }^{2,3}$. Moreover, algal polysaccharides significantly enhance wound-healing ability ${ }^{4}$.

Algae have been used for thousands of years ${ }^{5}$. Marine macroalgae, such as red and green algae, contain high levels of protein, polysaccharides, long-chain fatty acids, and other biocompounds ${ }^{6}$. Marine algal polysaccharides can aid energy storage and basal structure maintenance.

Many studies have reported the bioactivity of polysaccharides from algae, such as Arthrospira, Dunaliella, Haematococcus, Scenedesmus, and Sarcodia ${ }^{8-11}$. These polysaccharides have demonstrated positive in antitumour, cytokine-regulatory, and antiinflammatory bioactivity. Polysaccharides typically bind to dectin-1 and then activate the immune cell, such as macrophages, neutrophils, and dendritic cells ${ }^{12}$. Dectin-1, a C-type lectin family receptor, is expressed on cell membranes ${ }^{13}$. Dectin-1 binding to polysaccharides promotes phagocytosis, induces ROS production, enhances neutrophil degranulation, and induces immune cells to regulate cytokine production in macrophages ${ }^{14}$. The induced cytokines act as signalling moleculus that initiate cellular alteration.

Moreover, polysaccharides bind to the complement receptor type 3 (CR3) ${ }^{15}$. This receptor, expressed on immune cells, identifies polysaccharides ${ }^{16}$. When recognised, CR3 induces signalling to activate transcription factors. The major function of these transcription factors is inflammatory cytokine regulation.

\footnotetext{
${ }^{1}$ Department of Aquaculture, National Pingtung University of Science and Technology, Pingtung, Taiwan. ${ }^{2}$ Department of Aquaculture, National Taiwan Ocean University, Keelung, Taiwan. *email: wuys0313@mail.npust. edu.tw
} 


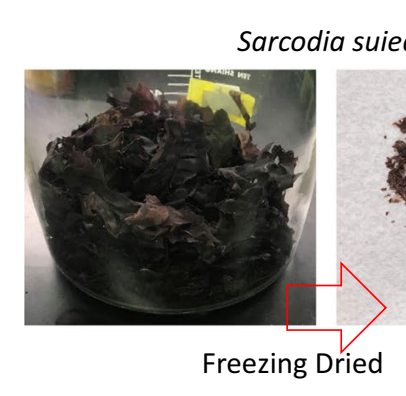

\section{suieae}

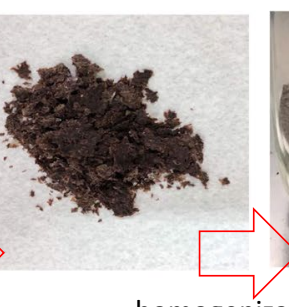

homogenization
Sarcodia suieae powder

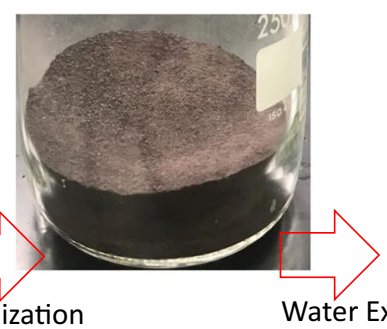

Water Extract

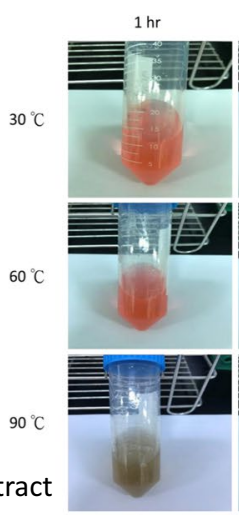

$6 \mathrm{hr}$
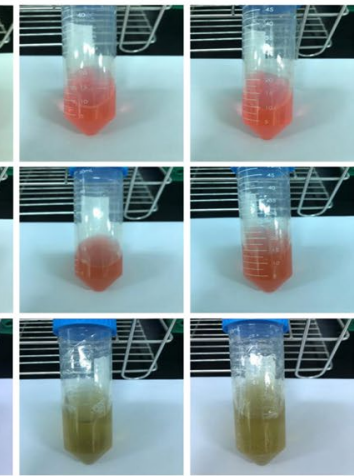

$99.8 \%$ ethanol pelleted and freezing dried
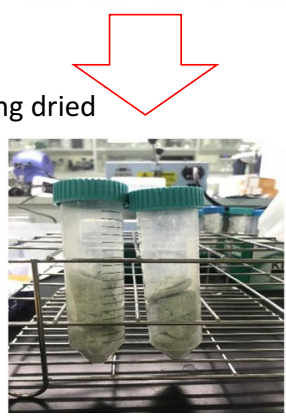

Figure 1. Process of acetyl-xylogalactan extraction from S. suieae.

Algal immunoregulatory substances include polysaccharides and proteins. However, to our knowledge, the mechanisms of most bioactive immunoregulatory substances involved in macrophage polarisation are somewhat unknown. This study investigated whether acetyl-xylogalactan from Sarcodia suieae induces macrophage polarisation. First, the monosaccharide and polysaccharide contents, monosaccharide composition, acetyl content, and molecular weight of this acetyl-xylogalactan were evaluated through MALDI-TOF mass spectrometry and NMR spectroscopy. Next, its effect on RAW 264.7 macrophage morphology alteration, phagocytic activity change, and interleukin (IL) 6 and IL-17A production was examined. Moreover, the treated RAW 264.7 macrophages were analysed to predict signal transduction through next-generation sequencing (NGS) and the related gene expression was examined using real-time qPCR.

\section{Materials and Methods}

S. suieae acetyl-xylogalactan extraction and analysis. S. suieae acetyl-xylogalactan was extracted from laboratory. S. suieae was collected from a commercial sea algae culture pond in Southern Taiwan. The collected S. suieae were freeze-dried and homogenised to a powder. This powder was soaked in water of various temperatures $\left(30^{\circ} \mathrm{C}, 60^{\circ} \mathrm{C}\right.$, and $\left.90^{\circ} \mathrm{C}\right)$ for various periods $(1,6$, and $12 \mathrm{~h})$ at a powder-to-double distilled water ratio of 1:40, so as to extract the water-soluble materials. Next, the sample was centrifuged at $4000 \mathrm{rpm}$ for 30 min to collect the supernatant. The extracted polysaccharide in the supernatant was pelleted using $99.8 \%$ waterfree ethanol (Sigma) (supernatant:water-free ethanol $=1: 3$ ) for $2 \mathrm{~h}$. The polysaccharide extraction procedure is presented in Fig. 1.

The monosaccharide and polysaccharide contents and monosaccharide components were analysed through MALDI-TOF mass spectrometry and NMR spectrometry ${ }^{17}$. The acetyl content and molecular weight were evaluated through NMR spectrometry ${ }^{18,19}$ by Sugarlighter, Taiwan.

RAW 264.7 macrophage culture. RAW 264.7 macrophages [Bioresource Collection and Research Center (BCRC) No. 60001] were purchased from BCRC, Food Industry Research and Development Institute, Hsinchu, Taiwan. After the cells were received by our laboratory, they were maintained in $90 \%$ Dulbecco's modified Eagle's medium with $10 \%$ foetal bovine serum, incubated at $37^{\circ} \mathrm{C}$ and $5 \% \mathrm{CO}_{2}$.

Toxicity effect of S. suieae acetyl-xylogalactan on RAW 264.7 macrophages. To examine the toxicity of S. suieae acetyl-xylogalactan to RAW 264.7 macrophages, the experiment groups were classified as control receiving no treatment and treatment groups treated with 10,20 , and $30 \mu \mathrm{g} / \mathrm{mL}$ S. suieae acetyl-xylogalactan.

In brief, RAW 264.7 macrophages $\left(1 \times 10^{6}\right.$ cells $)$ were treated with or without S. suieae acetyl-xylogalactan for 12 and $24 \mathrm{~h}$. At the end of the treatment, the cells were observed using the Cell Counting Kit-8 (CCK-8; B34302, Bimake) at an OD of $450 \mathrm{~nm}$.

Effect of S. suieae acetyl-xylogalactan on RAW 264.7 macrophages' phagocytic activity. The phagocytic activity of RAW 264.7 macrophages was determined using pHrodo Green BioParticles Conjugate for Phagocytosis (P35366, Thermo Scientific). In brief, $1 \times 10^{6}$ cells were cultured in the medium at $37^{\circ} \mathrm{C}$ and $5 \%$ $\mathrm{CO}_{2}$ for $24 \mathrm{~h}$. After incubation, 10,20, and $30 \mu \mathrm{g} / \mathrm{mL}$ S. suieae acetyl-xylogalactan was added to the cells and then 


\begin{tabular}{|c|c|c|c|c|c|c|c|c|c|c|c|}
\hline \multicolumn{2}{|c|}{$\begin{array}{l}\text { Extraction } \\
\text { Condition }\end{array}$} & \multirow{3}{*}{$\begin{array}{l}\text { Dried } \\
\text { Weight (g) }\end{array}$} & \multirow{3}{*}{$\begin{array}{l}\text { Water Extract Materials } \\
\text { Recovery Rate (\%) }\end{array}$} & \multicolumn{8}{|c|}{ Ethanol precipitation } \\
\hline \multirow[b]{2}{*}{ Temp. } & \multirow[b]{2}{*}{ Time } & & & \multirow{2}{*}{$\begin{array}{l}\text { 99.8\% ethanol } \\
\text { Recovery Rate (\%) }\end{array}$} & \multirow{2}{*}{$\begin{array}{l}\text { Polysaccharide } \\
\text { Content (\%) }\end{array}$} & \multicolumn{6}{|c|}{ Component of Monosaccharide (\%) } \\
\hline & & & & & & Glucose & Fructose & Sucrose & Galactose & Xylose & Others \\
\hline \multirow{3}{*}{$30^{\circ} \mathrm{C}$} & 1 hour & \multirow{9}{*}{1.000} & $13 \%$ & $5 \%$ & 50.6 & 2.4 & - & - & 83.0 & 14.6 & - \\
\hline & 6 hour & & $16 \%$ & $9 \%$ & 71.1 & - & - & - & 82.4 & 11.0 & 6.6 \\
\hline & 12 hour & & $17 \%$ & $6 \%$ & 78.8 & - & - & - & 64.8 & 35.2 & - \\
\hline \multirow{3}{*}{$60^{\circ} \mathrm{C}$} & 1 hour & & $18 \%$ & $6 \%$ & 67.0 & - & - & - & 89.1 & 7.8 & 3.1 \\
\hline & 6 hour & & $14 \%$ & $9 \%$ & 80.6 & - & - & - & 91.0 & 9.0 & - \\
\hline & 12 hour & & $21 \%$ & $8 \%$ & 75.2 & - & - & - & 90.7 & 7.8 & 1.5 \\
\hline \multirow{3}{*}{$90^{\circ} \mathrm{C}$} & 1 hour & & $18 \%$ & $9 \%$ & 52.3 & 72 & 25 & $<3$ & - & - & - \\
\hline & 6 hour & & $19 \%$ & $9 \%$ & 71.2 & 45 & 3 & 52 & - & - & - \\
\hline & 12 hour & & $22 \%$ & $12 \%$ & \begin{tabular}{|l|}
73.4 \\
\end{tabular} & 74 & $<3$ & 51 & - & - & - \\
\hline
\end{tabular}

Table 1. Water extraction results for S. suieae exposed to various temperatures for 1,6 , and $12 \mathrm{~h}$.

incubated for $24 \mathrm{~h}$. Next, the culture medium was removed and bioparticles were added, followed by incubation for $2 \mathrm{~h}$. At the end of the culture, the phagocytic activity was detected at Ex/Em of 509/533.

IL-6 and IL-17A production in RAW 264.7 macrophages. IL-6 and IL-17A production in the RAW 264.7 macrophages treated with or without $S$. suieae acetyl-xylogalactan was analysed. In brief, $1 \times$ $10^{6}$ RAW 264.7 macrophages were cultured in a 96-well plate with or without 10,20 , or $30 \mu \mathrm{g} / \mathrm{mL}$ S. suieae acetyl-xylogalactan at for $24 \mathrm{~h}$. The culture medium was then analysed using the ELISA IL-6 and IL-17A assay kit (QIAGEM, SEM03015A and SEM03023A) at an OD of $450 \mathrm{~nm}$.

RNA sequencing (transcriptome). RAW 264.7 macrophages $\left(1 \times 10^{6}\right.$ cells) were treated with or without 10,20 , or $30 \mu \mathrm{g} / \mathrm{mL}$ S. suieae acetyl-xylogalactan for $24 \mathrm{~h}$. Thereafter, RNA was isolated from the cells using Azol RNA Isolation Reagent (Arrowtech). RNA concentrations were determined using Nanodrop, and then, $1 \mu \mathrm{g}$ of RNA was sent to Biotools Co., Ltd., Taiwan for the RNA sequencing (RNA-seq; transcriptome) analysis, where NovaSeq. 6000 Sequencing System (Illumina) is used. The reference genome mapped using HISAT2. Only filtered reads could be used to analyse the mapping status of RNA-seq data to the reference genome.

Real-time reverse transcription qPCR for gene expression. Total RNA was extracted using Azol RNA Isolation Reagent (Arrowtech) and quantified through spectrophotometry at $260 \mathrm{~nm}$. Real-time qPCR analysis of the macrophage IL-1 $\beta$, TNF, and Malt-1 was performed by Biotools Co., Ltd.. GAPDH was used as the reference in the comparative CT to determine the relative alteration. Fluorescence was analysed using the auto CT method to determine the threshold of each gene, and the $2^{-\Delta \Delta C T}$ method was used to calculate CT values by using StepOne (version 2.3). Data are presented as fold changes in the mRNA level normalised to the reference gene GAPDH.

The following oligonucleotide sequences were used for creating qPCR primers:

\begin{tabular}{|l|l|l|}
\hline Gene & Forward primer & Reverse primer \\
\hline IL-1 b & TGGACCTTCCAGGATGAGGACA & GTTCATCTCGGAGCCTGTAGTG \\
\hline TNF & GGTGCCTATGTCTCAGCCTCTT & GCCATAGAACTGATGAGAGGGAG \\
\hline Malt-1 & GAACTGAGCGACTTCCTACAGG & AACTGTCCAGCCAACACTGCCT \\
\hline GAPDH & CATCACTGCCACCCAGAAGACTG & ATGCCAGTGAGCTTCCCGTTCAG \\
\hline
\end{tabular}

Statistical analysis. Scheffés test and one-way ANOVA were used to analyse the statistical significance between the treatment and control groups. A p-value of $<0.05$ was considered statistically significant. The results are presented as the means $\pm \mathrm{SD}(\mathrm{p}<0.05$ and $\mathrm{p}<0.001)$. For RNA-seq data, DEGseq was used to analyse significant differences between the treatment and control groups. A relative log expression of $>2$ and a corrected p-value of $<0.005$ were considered statistically significant.

\section{Results}

S. suieae acetyl-xylogalactan extraction and analysis. Acetyl-xylogalactan was extracted from $S$. suieae by using hot water and then extracted using ethanol (Fig. 1). In brief, the water-soluble materials were extracted from freeze-dried S. suieae powder by using hot water $\left(60^{\circ} \mathrm{C}\right)$ for $6 \mathrm{~h}$, and then, acetyl-xylogalactan was obtained from the aqueous supernatant through $99.8 \%$ ethanol extraction.

The polysaccharide analysis results are presented in Table 1 . The recovery rate for water extraction was $14 \%$, followed by a polysaccharide recovery rate was $9 \%$ at $60^{\circ} \mathrm{C}$ for $6 \mathrm{~h}$. Although we performed polysaccharide extraction at $30^{\circ} \mathrm{C}, 60^{\circ} \mathrm{C}$, and $90^{\circ} \mathrm{C}$, only extraction at $60^{\circ} \mathrm{C}$ for $6 \mathrm{~h}$ afforded a desirable monosaccharide composition of $91 \%$ galactose and $9 \%$ xylose (Table 2). Furthermore, its polysaccharide and acetyl contents were nearly $80.6 \%$ and $19.3 \%$, respectively, and its molecular weight was $88.5 \mathrm{kDa}$. Thus, this relative pure acetyl-xylogalactan was selected for the further investigation. 


\begin{tabular}{|c|c|c|c|c|c|c|c|}
\hline \multirow[b]{2}{*}{$\begin{array}{l}\text { Dried } \\
\text { Weight (g) }\end{array}$} & \multirow[b]{2}{*}{$\begin{array}{l}\text { Water Extract Materials } \\
\text { Recovery Rate (\%) }\end{array}$} & \multicolumn{6}{|c|}{ Ethanol precipitation } \\
\hline & & \begin{tabular}{|l|} 
99.8\% ethanol \\
Recovery Rate (\%)
\end{tabular} & $\begin{array}{l}\text { Polysaccharide } \\
\text { Content (\%) }\end{array}$ & \multicolumn{2}{|c|}{\begin{tabular}{|l|} 
Component of \\
Monosaccharide (\%)
\end{tabular}} & \begin{tabular}{|l|} 
Acetyl \\
Content(\%)
\end{tabular} & \begin{tabular}{|l|} 
Molecular \\
Weight (kDa)
\end{tabular} \\
\hline \multirow{2}{*}{1.000} & \multirow{2}{*}{14} & \multirow{2}{*}{ 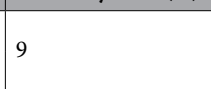 } & \multirow{2}{*}{80.6} & Galactose & 91 & \multirow{2}{*}{19.3} & \multirow{2}{*}{88.5} \\
\hline & & & & Xylose & 9 & & \\
\hline
\end{tabular}

Table 2. Ethanol extraction of polysaccharide. Polysaccharide collection was performed at $60^{\circ} \mathrm{C}$ for $6 \mathrm{~h}$. '-': not detected.

a

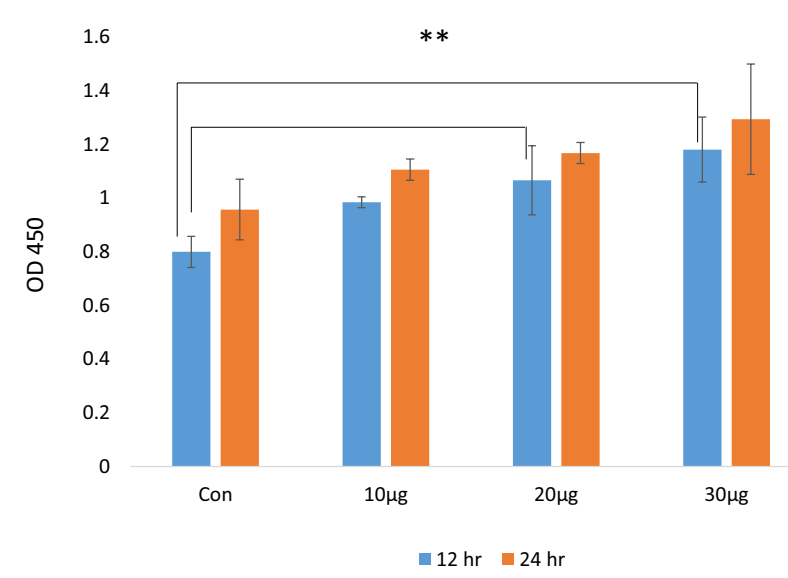

b

\begin{tabular}{|c|c|c|c|c|}
\hline Treatment & Gene Id & Symbol & Fold Change & $P$ value \\
\hline $10 \mu \mathrm{g} / \mathrm{ml}$ & \multirow{3}{*}{ ENSMUSG00000063229 } & \multirow{3}{*}{ lactate dehydrogenase $\mathrm{A}$} & 0.3131 & $8.9 \mathrm{E}-12$ \\
\hline $20 \mu \mathrm{g} / \mathrm{ml}$ & & & 0.4118 & 4.5E-11 \\
\hline $30 \mu \mathrm{g} / \mathrm{ml}$ & & & 0.5853 & $1.4 \mathrm{E}-30$ \\
\hline
\end{tabular}

Figure 2. Toxicity assessment in RAW 264.7 macrophages treated with or without $S$. suieae acetyl-xylogalactan after 12 and 24 incubation. $* \mathrm{p}<0.05, * * \mathrm{p}<0.01(\mathrm{n}=5)$.

Toxicity of S. suieae acetyl-xylogalactan to RAW 264.7 macrophages. RAW 264.7 macrophages were treated with 10,20 , and $30 \mu \mathrm{g} / \mathrm{mL}$ acetyl-xylogalactan for 12 and $24 \mathrm{~h}$ and compared with untreated cells. The results indicated RAW 264.7 macrophages toxicity was not reduced in the experiment. After $12 \mathrm{~h}$, the 20and $30-\mu \mathrm{g} / \mathrm{mL}$ treatment groups demonstrated significant difference compared with the control group ( $\mathrm{p}<0.05$; Fig. 2a), which diminished after $24 \mathrm{~h}$ ( $\mathrm{p}>0.05$ ). Moreover, at $24 \mathrm{~h}$, NGS detection of the fold changes in gene expression demonstrated significant induction of lactate dehydrogenase expression $(\mathrm{p}<0.05)$. Thus, S. suieae acetyl-xylogalactan was not considered to be acutely toxic to RAW 264.7 macrophages.

Cellular toxicity was next observed using the CCK-8 assay, in which detection occurs when WST-8 [2-(2-met hoxy-4-nitrophenyl)-3-(4-nitrophenyl)-5-(2,4-disulfophenyl)-2H-tetrazolium,monosodium salt] is reduced by dehydrogenases to form formazan (orange in colour). In this context, RNA-seq analysis demonstrated non-significant lactate dehydrogenase A expression after treatment concentration for $24 \mathrm{~h}$ (Fig. $2 \mathrm{~b}$ ).

Effect of S. suieae acetyl-xylogalactan on RAW 264.7 macrophages' phagocytic activity. The effects of the acetyl-xylogalactan on RAW 264.7 macrophages' phagocytic activity are presented in Fig. 3a. At $12 \mathrm{~h}$, compared with control, $30 \mu \mathrm{g} / \mathrm{mL}$ acetyl-xylogalactan treatment significantly increased RAW $264.7 \mathrm{mac}-$ rophages' phagocytic ability $(\mathrm{p}<0.05)$, but the effect of 10 and $20 \mu \mathrm{g} / \mathrm{mL}$ acetyl-xylogalactan was non-significant $(\mathrm{p}>0.05)$. After $24 \mathrm{~h}$, these changes in the phagocytic ability became non-significant in all groups $(\mathrm{p}>0.05)$. Moreover, acetyl-xylogalactan treatment led to morphology alterations in RAW 264.7 macrophages: RAW 264.7 macrophages polarised to a fusiform shape was noted (Fig. 3b).

IL-6 and IL-17A production of the RAW 264.7 macrophages. Acetyl-xylogalactan regulated IL6 and IL 17A production in RAW 264.7 macrophages (Fig. 4). Compared with the control, IL-6 levels significantly decreased after treatment with 20 and $30 \mu \mathrm{g} / \mathrm{mL}$ acetyl-xylogalactan $(\mathrm{p}<0.05)$, but this change was non-significant for $10 \mu \mathrm{g} / \mathrm{mL}$ acetyl-xylogalactan ( $\mathrm{p}>0.05$; Fig. $4 \mathrm{a})$. Moreover, compared with the other groups, IL-17A levels significantly decreased only after treatment with $30 \mu \mathrm{g} / \mathrm{mL}$ acetyl-xylogalactan $(\mathrm{p}<0.05 ;$ Fig. $4 \mathrm{~b})$. At $24 \mathrm{~h}$, RNA-seq for detection of the fold change in IL6 expression also demonstrated nonsignificant differences for all groups ( $p>0.05$ ), but RNA-seq analysis for IL17A was not performed.

Thus, the extracted $S$. suieae acetyl-xylogalactan can regulate the production of macrophage cytokines, responsible for macrophage polarisation. 


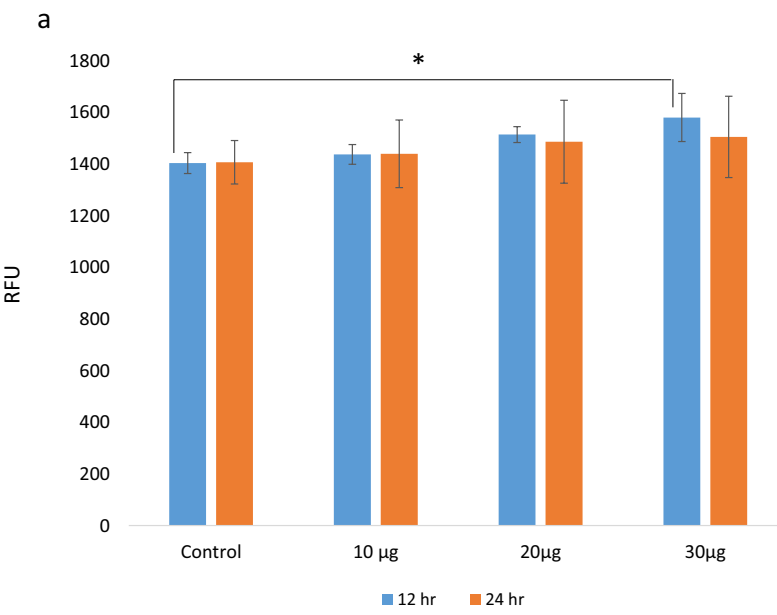

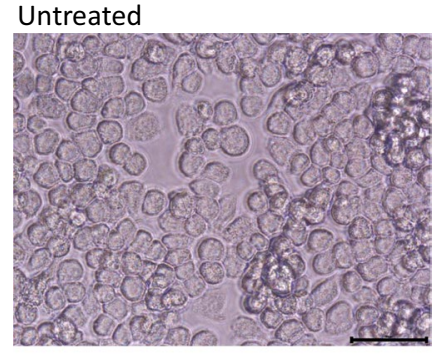

Treated

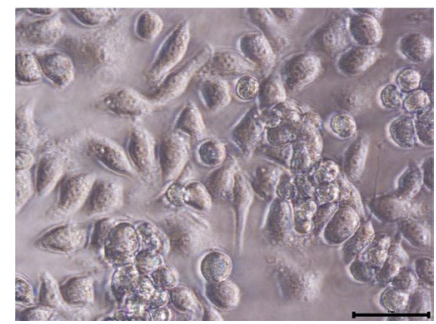

Figure 3. (a) Phagocytic ability of RAW 264.7 macrophages with or without S. suieae acetyl-xylogalactan treatment. ${ }^{*} \mathrm{p}<0.05$. (b) Microscopic observation of the phagocytosis by RAW 264.7 macrophages treated with or without $S$. suieae acetyl-xylogalactan. Black bar $=50 \mu \mathrm{m} .(\mathrm{n}=5)$.

(a) IL-6

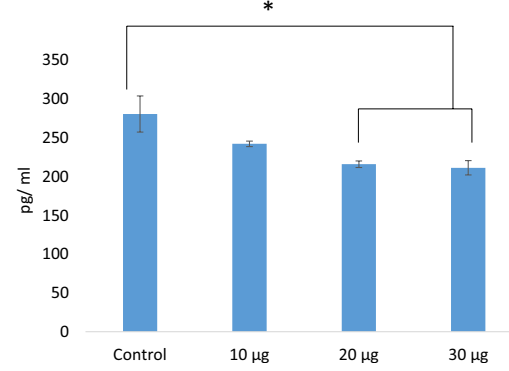

\begin{tabular}{|c|c|c|c|c|}
\hline 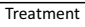 & Gene Id & Symbol & \begin{tabular}{|l} 
Fold Change \\
\end{tabular} & \begin{tabular}{|l|} 
P value \\
\end{tabular} \\
\hline $10 \mu \mathrm{g} / \mathrm{ml}$ & \multirow{3}{*}{ ENSMUSG00000025746 } & \multirow{3}{*}{ IL6 } & 0.2532 & 0.95 \\
\hline $20 \mu \mathrm{g} / \mathrm{ml}$ & & & -0.37959 & 0.89 \\
\hline $30 \mu \mathrm{g} / \mathrm{ml}$ & & & 0.2256 & 0.98 \\
\hline
\end{tabular}

(b) IL-17A

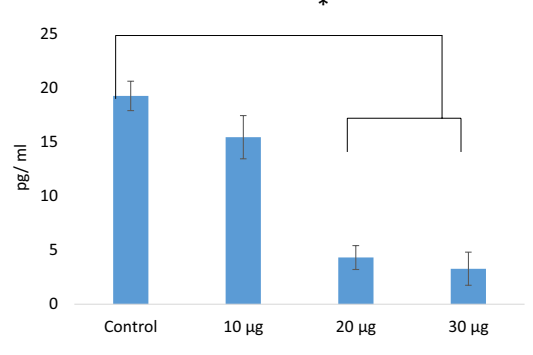

\begin{tabular}{|l|c|c|l|l|}
\hline Treatment & Gene Id & Symbol & Fold Change & Pvalue \\
\hline $10 \mu \mathrm{\mu g} / \mathrm{ml}$ & & - & - & \\
\cline { 1 - 1 } $20 \mathrm{\mu g} / \mathrm{ml}$ & & - & - & \\
\hline $30 \mathrm{\mu g} / \mathrm{ml}$ & & & & \\
\hline
\end{tabular}

".," means not detected.

Figure 4. IL-6 and IL-17A production was observed from RAW 264.7 macrophages treated for 24 h. *p $<0.05$, $* * \mathrm{p}<0.01(\mathrm{n}=5)$

\begin{tabular}{|l|l|l|l|l|}
\hline Sample name & Con & $\mathbf{1 0} \mu \mathbf{g} / \mathbf{m l}$ & $\mathbf{2 0} \boldsymbol{\mu g} / \mathbf{m l}$ & $\mathbf{3 0} \boldsymbol{\mu g} / \mathbf{m l}$ \\
\hline Total reads & 45082648 & 40039902 & 56093708 & 50170644 \\
\hline Total mapped & $42730250(94.78 \%)$ & $37706492(94.17 \%)$ & $52873876(94.26 \%)$ & $47371721(94.42 \%)$ \\
\hline Multiple mapped & $2749339(6.10 \%)$ & $2357681(5.89 \%)$ & $3239878(5.78 \%)$ & $2913806(5.81 \%)$ \\
\hline Uniquely mapped & $39980911(88.68 \%)$ & $35348811(88.28 \%)$ & $49633998(88.48 \%)$ & $44457915(88.61 \%)$ \\
\hline
\end{tabular}

Table 3. Mapping to Reference Genome. Total reads: Total number of filtered reads; Total mapped: Total number of reads that could be mapped to the genome (this values is typically $>70 \%$ when no contamination has occurred and the reference genome has been accurately selected); Multiple mapped: Total number of reads that could be mapped to multiple sites in the reference genome (should be $<10 \%$ typically); Uniquely mapped: Total number of reads that could be uniquely mapped to the reference genome.

RNA-seq (transcriptome) and real-time reverse transcription qPCR. RNA was extracted from RAW 264.7 macrophages and first mapped to the reference genome (Table 3). Multiple mapped reference genome counts were $<10 \%$, and the unique mapped counts to the reference genome were nearly $88 \%$. In other words, the isolated RNA could be accurately mapped to the mouse reference genome. 
$10 \mu \mathrm{g} \quad 20 \mu \mathrm{g}$

b

200.

a

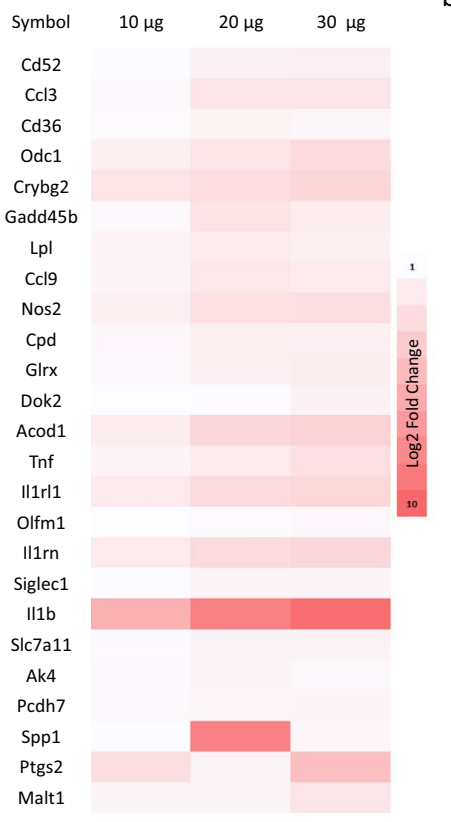

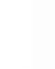

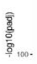

$30 \mu \mathrm{g}$
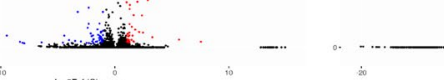

bogeracchonge
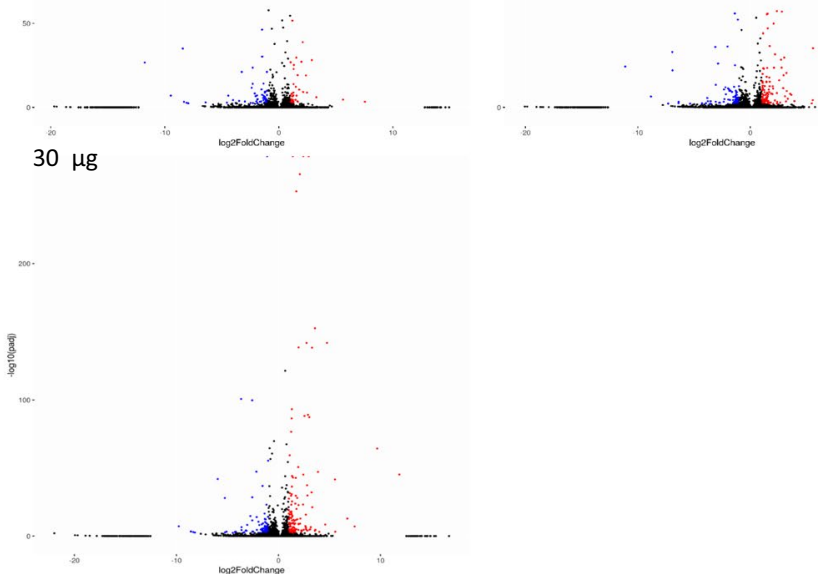

C

IL-1 b

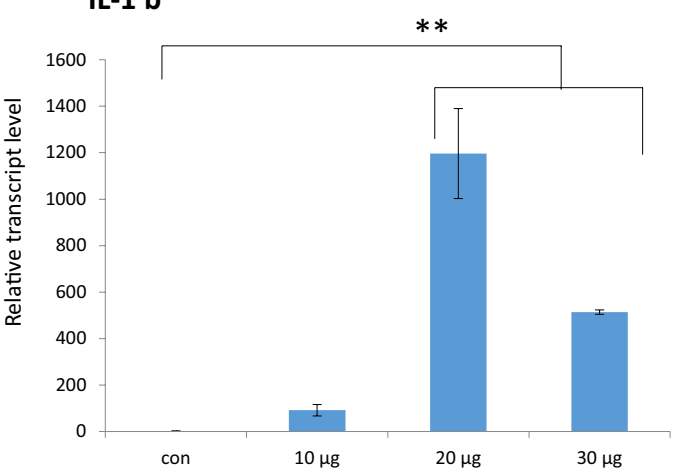

Malt-1

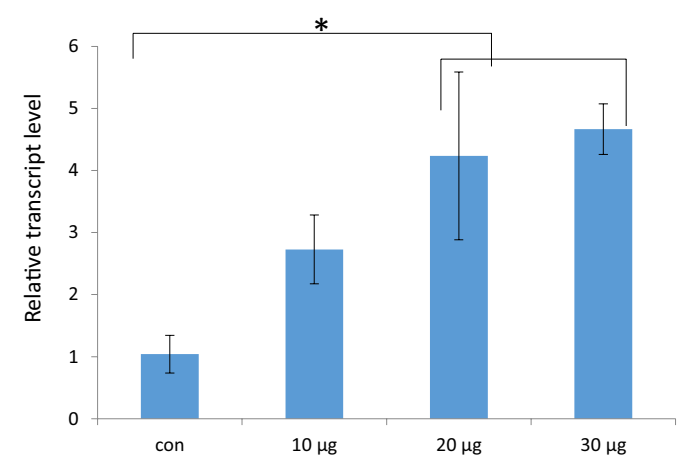

TNF

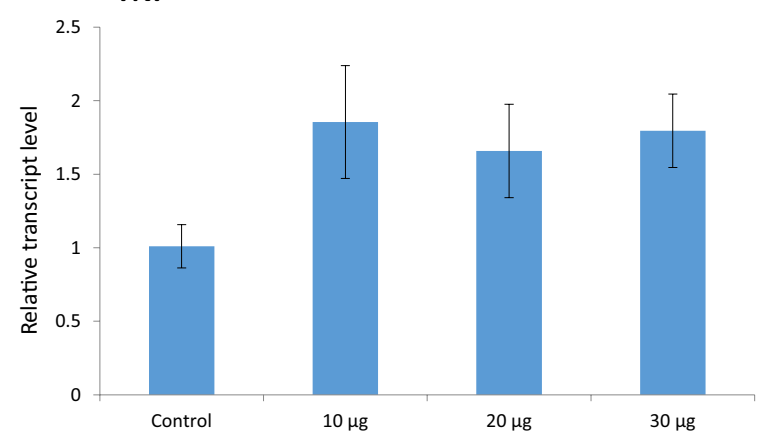

Figure 5. RNA-seq analysis of RAW 264.7 macrophages treated for 24 h. (a) Heatmap of the principal component analysis (PCA). (b) Volcano map of gene expression fold change and p-value significance change. (c) Real-time qPCR of $I L 1 B, T N F$, and MALT1 expression $(\mathrm{n}=3)$. C_10, C_20, and C_30 indicate 10, 20, and 30 $\mu \mathrm{g} / \mathrm{mL}$ S. suieae acetyl-xylogalactan treatment, respectively.

RNA-seq analysis further revealed that $S$. suieae acetyl-xylogalactan treatment significantly altered the RNA gene expression. The log2 fold change in gene expression is presented in Fig. 5a. Acetyl-xylogalactan treatment increased RNA gene expression of TNF, IL1B, MALT1, and other genes in RAW 264.7 macrophages, as presented in the heatmap in Fig. 5a.

A volcano map (Fig. 5b) of the biological effects (log2 fold change) and their statistical significance $(-\log 10$ p-value) was used to compare the alteration in gene expression in the treatments with control. In the volcano map, the red spots represent the differentially expressed genes significantly upregulated by the treatment $(\mathrm{p}<0.005$, 

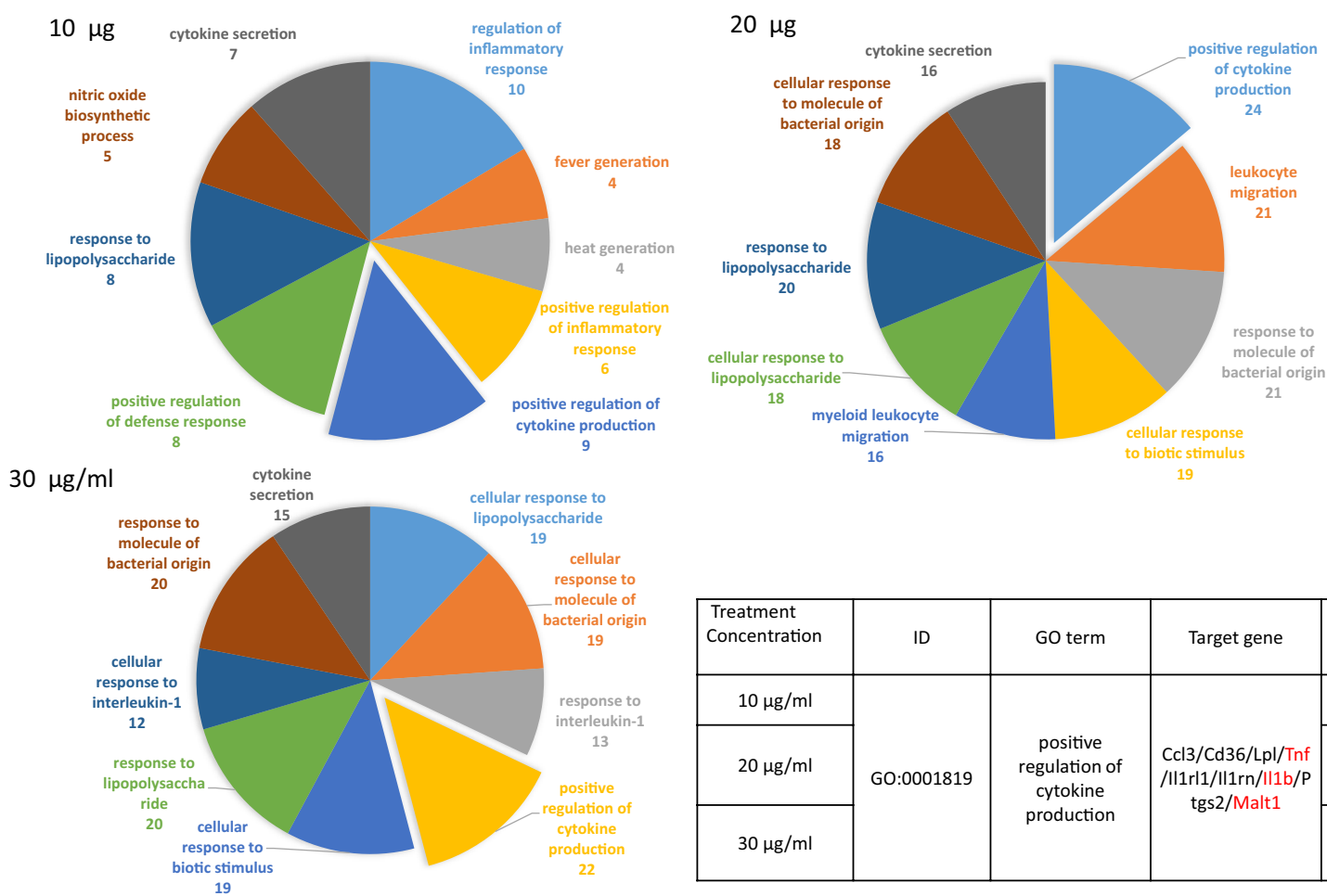

\begin{tabular}{|c|c|c|c|c|}
\hline \begin{tabular}{|l|} 
Treatment \\
Concentration
\end{tabular} & ID & GO term & Target gene & $p$-value \\
\hline $10 \mu \mathrm{g} / \mathrm{ml}$ & \multirow{3}{*}{ GO:0001819 } & \multirow{3}{*}{$\begin{array}{l}\text { positive } \\
\text { regulation of } \\
\text { cytokine } \\
\text { production }\end{array}$} & \multirow{3}{*}{$\begin{array}{c}\mathrm{Ccl} 3 / \mathrm{Cd} 36 / \mathrm{Lpl} / \mathrm{Tnf} \\
/ / 1 \mathrm{rl} 1 / \mathrm{II} \mathrm{rn} / \mathrm{Il} \mathrm{b} / \mathrm{P} \\
\text { tgs2/Malt1 }\end{array}$} & $\begin{array}{c}0.00000034669 \\
78\end{array}$ \\
\hline $20 \mu \mathrm{g} / \mathrm{ml}$ & & & & $\begin{array}{c}0.00000000000 \\
2110217\end{array}$ \\
\hline $30 \mu \mathrm{g} / \mathrm{ml}$ & & & & $\begin{array}{c}0.00000000000 \\
956199\end{array}$ \\
\hline
\end{tabular}

Figure 6. GO term prediction demonstrating S. suieae acetyl-xylogalactan facilitated the regulation of cytokine production. Predicted expressed genes included CCL3, CD36, LPL, TNF, IL1RL1, IL1RN, IL1B, PTGS2, and MALT1.

$\log 2$ fold change $>2$ ). Real-time qPCR results for the IL-1 $\beta$, TNF and Malt-1 terms are presented in Fig. $5 c$. M1 macrophage conversion was observed in RAW 264.7 macrophages treated with S. suieae acetyl-xylogalactan: 20 and $30 \mu \mathrm{g} / \mathrm{mL}$ acetyl-xylogalactan treatments significantly increased IL-1 $\beta$ expression nearly 400 - and 600 -fold, respectively (both $\mathrm{p}<0.01$ ). For Malt-1 expression, the relative transcript level increased approximately sixfold in the 20 and $30 \mu \mathrm{g} / \mathrm{mL}$ acetyl-xylogalactan treatment groups $(\mathrm{p}<0.05)$. However, TNF expression did not significantly differ between the control and treatment groups $(\mathrm{p}>0.05)$.

The predicted expressed genes CCL3, CD36, LPL, TNF, IL1RL1, IL1RN, IL1B, PTGS2, and MALT1 had positive functions in the regulation of cytokine production, as presented the GO term analysis (Fig. 6).

Taken together, these findings indicate that $S$. suieae acetyl-xylogalactan aided the M0 to M1 macrophage conversion. Pathway analyses revealed significantly upregulation of NF-kappa B signalling pathway components. Moreover, S. suieae acetyl-xylogalactan induced the expression of IL1B, TNF, and MALT1, which are involved in signalling transduction processes, based on KEGG observations presented in Fig. 7.

\section{Discussion}

In this study, the regulatory effects of $S$. suieae acetyl-xylogalactan were investigated in RAW 264.7 macrophages. RAW 264.7 macrophages were treated with various concentrations of the S. suieae acetyl-xylogalactan and then the cellular response was analysed using microscopic observation and RNA-seq methods. The findings revealed that S. suieae acetyl-xylogalactan positively regulates cytokine production and activates the NF-kappa B signalling pathway.

Studies have linked the signalling mechanisms to inflammation regulation: NF- $\kappa$ B signalling regulates expression of cytokines (e.g., IL-1, IL-6, IL-8, and TNF) and chemokines and modulates adhesion molecules and cell-cycle regulatory molecules ${ }^{20}$. NF- $\kappa \mathrm{B}$, a transcription factor, has several functions in macrophages ${ }^{21}$, categorised into M1 and M2 macrophages: M1 macrophages release pro-inflammatory cytokines, such as IL-1, IL-6, IL-12, and TNF, which regulate inflammation response ${ }^{22}$. On stimulation, transforming growth factor- $\beta$-activated kinase 1 (TAK1) is first activated to induce the downstream kinase multisubunit I B kinase complex (IKK) response $^{23}$. Activated IKK can phosphorylate and degrade the NF- $\kappa \mathrm{B}$ inhibitor, $\mathrm{\kappa} \kappa \mathrm{B} \alpha$, and cause NF- $\kappa \mathrm{B}$ activation $^{24}$. Activated NF- $\kappa B$ is responsible for the conversion of M0 macrophages to M1 macrophages and for cytokine production.

A Lycium barbarum polysaccharide could promote TNF- $\alpha$ and IL-1 $\beta$ production ${ }^{25}$. A signalling pathway analysis revealed that it enhanced $\mathrm{p} 38$-MAPK phosphorylation and reduced JNK and ERK1/2 MAPK phosphorylation $^{26}$. Moreover, a study on the effects of a purified Laminaria japonica polysaccharide on the cytokine production in RAW 264.7 macrophages demonstrated that TNF and IL-1 $\beta$ increased with sample concentration $^{26}$. Additionally, NF- $\kappa B$ p65 levels significantly increased after the Laminaria japonica polysaccharide treatment $^{27}$. According to our findings in RAW 264.7 macrophages treated with S. suieae acetyl-xylogalactan for 24 


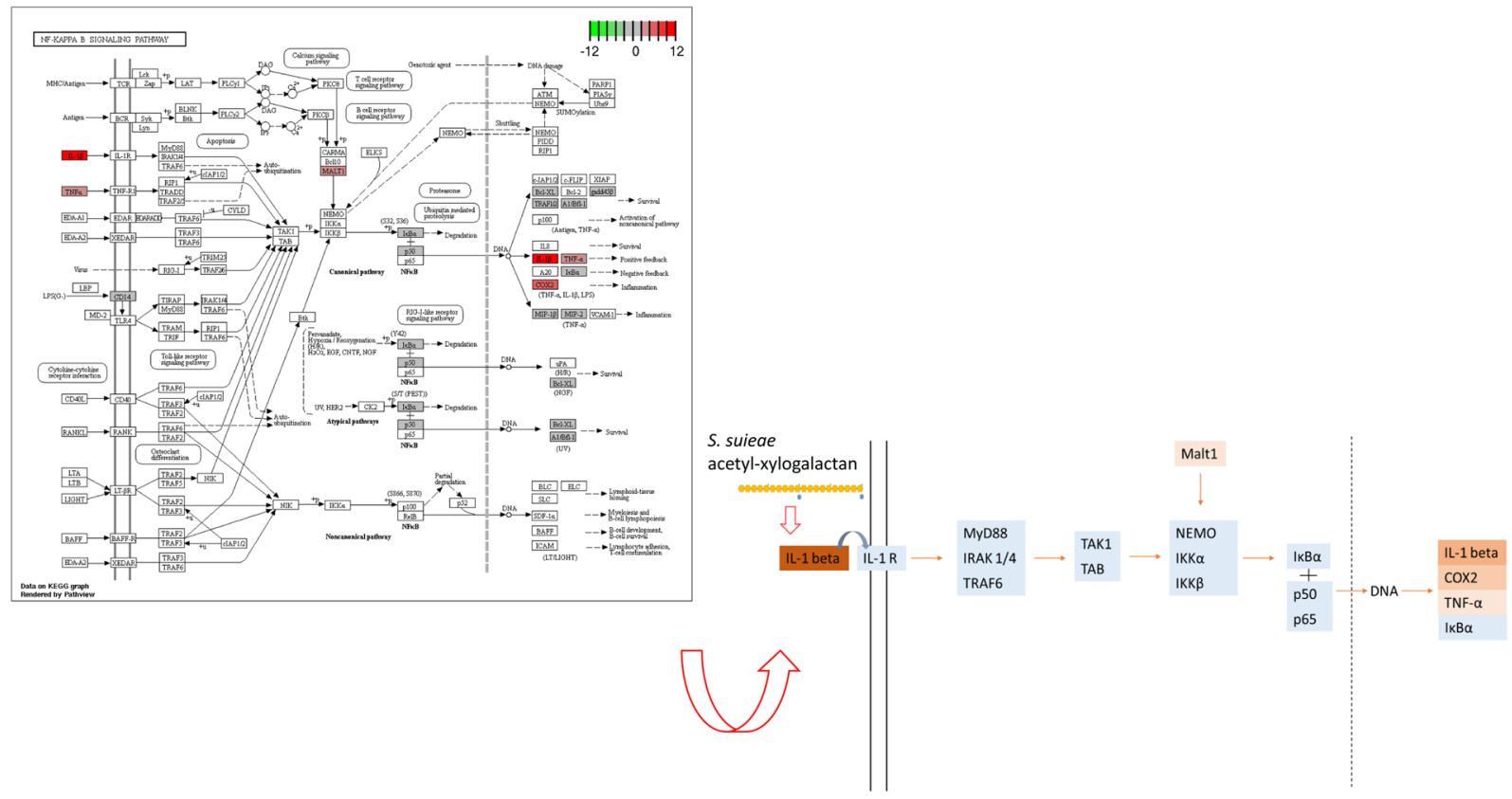

Figure 7. Predicted pathway illustrated that $I L 1 B$ and $M A L T 1$ were significantly upregulated in the NF-kappa B signalling pathway.

h, real-time PCR results revealed increased TNF, IL-1 $\beta$, and Malt-1 levels, ELISA demonstrated reduced IL-6 and IL-17 levels. Other studies have reported that IL-6 production is typically involved in the host defence observed in the infection or wounded tissues during the acute-phase response. In the current study, S. suieae acetyl-xylogalactan treatment did not cause toxicity to RAW 264.7 macrophages; hence, IL-6 and IL-17A must have not been produced. Thus, S. suieae acetyl-xylogalactan possibly increases the production of inflammation cytokines, such as TNF, IL-1 $\beta$, and Malt-1, but inhibits that of acute proinflammatory cytokines, such as IL-6 and IL-17A.

Acetylated Bletilla striata polysaccharide modulates macrophage activation and wound healing ${ }^{28}$. Addition of methyl, acetyl, sulphate, and phosphate groups to polysaccharides increases the complexity of their primary structure and enhances their biological functions ${ }^{29}$. Compared with the nonacetyl polysaccharide, acetyl polysaccharides have antioxidant abilities and can inhibit the $\beta$-carotene-linoleic acid system; they also increase TNF- $\alpha$ expression by approximately $25 \%$. The proposed underlying immunomodulatory mechanisms of these acetyl groups involve their interaction with the specific receptors and stimulation of the macrophage activation ${ }^{30}$. In this study, S. suieae acetyl-xylogalactan contained $19.3 \%$ acetyl groups and had a molecular weight of $88.5 \mathrm{kDa}$. Regarding the relationship between the $S$. suieae acetyl-xylogalactan and immunomodulation activation, the acetyl groups possibly facilitates the maintenance of the polysaccharide structure and their interaction with the cell-specific receptors to finally activate RAW 264.7 macrophages.

This study investigated the cellular functions of RAW 264.7 macrophages treated with S. suieae acetyl-xylogalactan. In the RNA-seq analysis, the $S$. suieae acetyl-xylogalactan was demonstrated to have positively regulated cytokine production and secretion, protein secretion, and response to the IL-1 activation, based on the observed GO terms. Of the predicted target genes in the GO enrichment analysis, CCL3, CD36, LPL, TNF, $I L 1 R L 1, I L 1 R N, I L 1 B, P T G S 2$, and MALT1, all involved in the NF- $\kappa B$ signalling pathway, were upregulated. Taken together, S. suieae acetyl-xylogalactan induced the NF- $\kappa B$ signalling pathway in macrophages by the KEGG database, thus eliciting an immune response ${ }^{31}$.

In conclusion, polysaccharide from the animals, plants, microorganisms and macro-algae was known

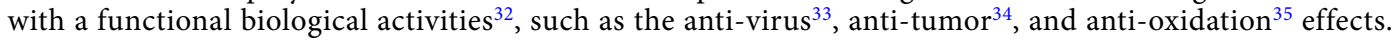
Summarization of our findings, we observed that the extracted S. suieae acetyl-xylogalactan might directly induce TNF, IL-1, and Malt1 production but reduces IL-6 and IL-17A production, resulting in regulating inflammation

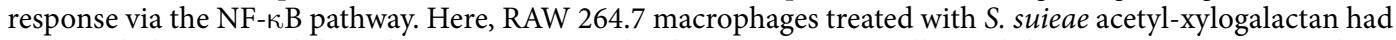
increased phagocytic ability. Thus, S. suieae acetyl-xylogalactan potentially modulates RAW 264.7 macrophage activation and polarisation to M1 macrophages.

Received: 30 August 2019; Accepted: 9 December 2019;

Published online: 23 December 2019

\section{References}

1. Lubbers, R., Van Essen, M., Van Kooten, C. \& Trouw, L. Production of complement components by cells of the immune system. Clin Exp Immunol. 188, 183-194 (2017).

2. Chen, L. \& Huang, G. Antitumor activity of polysaccharides: an overview. Curr Drug Targets. 19, 89-96 (2018). 
3. Yu, Y., Shen, M., Song, Q. \& Xie, J. Biological activities and pharmaceutical applications of polysaccharide from natural resources: A review. Carbohydr Polym. 183, 91-101 (2018).

4. Kumar, S., Marrero-Berrios, I., Kabat, M. \& Berthiaume, F. Recent Advances in the Use of Algal Polysaccharides for Skin Wound Healing. Curr Pharm Des. https://doi.org/10.2174/1381612825666190521120051 (2019).

5. Wells, M. L. et al. Algae as nutritional and functional food sources: revisiting our understanding. J Appl Phycol. 29, 949-982 (2017).

6. Shankar, P. D. et al. A review on the biosynthesis of metallic nanoparticles (gold and silver) using bio-components of microalgae: Formation mechanism and applications. Enzyme Microb Technol. 95, 28-44 (2016).

7. Wang, H. M. D., Li, X. C., Lee, D. J. \& Chang, J. S. Potential biomedical applications of marine algae. Bioresour Technol. 244, $1407-1415$ (2017).

8. Ruperez, P. \& Saura-Calixto, F. Dietary fibre and physicochemical properties of edible Spanish seaweeds. Eur Food Res Technol. 212, 349-354 (2001)

9. Fimbres-Olivarria, D. et al. Chemical characterization and antioxidant activity of sulfated polysaccharides from Navicula sp. Food Hydrocoll. 75, 229-236 (2018).

10. Kim, D. Y. et al. Cell-wall disruption and lipid/astaxanthin extraction from microalgae: Chlorella and Haematococcus. Bioresour. Technol. 199, 300-310 (2016).

11. He, J., Xu, Y., Chen, H. \& Sun, P. Extraction, structural characterization, and potential antioxidant activity of the polysaccharides from four seaweeds. Int J Mol Sci. 17, 1988 (2016).

12. Deng, C., Fu, H., Shang, J., Chen, J. \& Xu, X. Dectin-1 mediates the immunoenhancement effect of the polysaccharide from Dictyophora indusiata. Int J Biol Macromol. 109, 369-374 (2018).

13. Saijo, S. Roles of C-Type Lectin Receptors in Inflammatory Responses. Chronic Inflammation. pp. 333-344 (Springer, Tokyo, 2016).

14. Allen, L. A. H. \& Criss, A. K. Cell intrinsic functions of neutrophils and their manipulation by pathogens. Curr Opin Immunol. 60, 124-129 (2019)

15. Liu, C., Choi, M. W., Li, X. \& Cheung, P. C. Immunomodulatory effect of structurally-characterized mushroom sclerotial polysaccharides isolated from Polyporus rhinocerus on human monoctyes THP-1. J Funct Foods. 41, 90-99 (2018).

16. Li, W. et al. Mannose receptor mediates the immune response to Ganoderma atrum polysaccharides in macrophages. J Agric Food Chem. 65, 348-357 (2017).

17. Lin, C. et al. I2-catalyzed oxidative condensation of aldoses with diamines: Synthesis of aldo-naphthimidazoles for carbohydrate analysis. Molecules. 15, 1340-1353 (2010).

18. Wu, D., Chen, A. \& Johnson, C. S. An improved diffusion-ordered spectroscopy experiment incorporating bipolar-gradient pulses. J. Magn. Reson. Series A. 115, 260-264 (1995).

19. Viel, S., Capitani, D., Mannina, L. \& Segre, A. Diffusion-ordered NMR spectroscopy: a versatile tool for the molecular weight determination of uncharged polysaccharides. Biomacromolecules. 4, 1843-1847 (2003).

20. Li, Q. \& Verma, I. M. NF-kB regulation in the immune system. Nat Rev Immunol. 2, 725-734 (2002).

21. Murray, P. J. \& Wynn, T. A. Protective and pathogenic functions of macrophage subsets. Nat Rev Immunol. 11, $723-737$ (2011).

22. Sica, A. et al. Macrophage polarization in tumour progression. Semin Cancer Viol. 18, 349-355 (2008).

23. Liu, T., Zhang, L., Joo, D. \& Sun, S. C. NF-kB signaling in inflammation. Signal Transduct Target Ther. 2, e17023 (2017).

24. Zaidi, A. H. \& Manna, S. K. Profilin-PTEN interaction suppresses NF- $\mathrm{B}$ B activation via inhibition of IKK phosphorylation. Biochem J. 473, 859-872 (2016).

25. Ferreira, S. S., Passos, C. P., Madureira, P., Vilanova, M. \& Coimbra, M. A. Structure-function relationships of immunostimulatory polysaccharides: A review. Carbohydr Polym. 132, 378-396 (2015).

26. Fang, Q. et al. Immunomodulatory activity on macrophage of a purified polysaccharide extracted from Laminaria japonica. Carbohydr Polym. 134, 66-73 (2015).

27. Zha, X.-Q. et al. Structural identification and immunostimulating activity of a Laminaria japonica polysaccharide. Int J Biol Macromol. 78, 429-438 (2015).

28. Peng, Q., Li, M., Xue, F. \& Liu, H. Structure and immunobiological activity of a new polysaccharide from Bletilla striata. Carbohydr Polym. 107, 119-123 (2014).

29. Liu, X. et al. Preliminary characterization of the structure and immunostimulatory and anti-aging properties of the polysaccharide fraction of Haematococcus pluvialis. RSC Adv. 8, 9243-9252 (2018).

30. Chen, Y. et al. Acetylation and carboxymethylation of the polysaccharide from Ganoderma atrum and their antioxidant and immunomodulating activities. Food Chem. 156, 279-288 (2014).

31. Kanehisa, M., Sato, Y., Furumichi, M., Morishima, K. \& Tanabe, M. New approach for understanding genome variations in KEGG. Nucleic Acids Res. 47, 590-595 (2019).

32. Chen, F. \& Huang, G. Preparation and immunological activity of polysaccharides and their derivatives. Int J Biol Macromol. 112, 211-216 (2018)

33. Chen, L. \& Huang, G. The antiviral activity of polysaccharides and their derivatives. Int J Biol Macromol. 115, 77-82 (2018).

34. Huang, G. \& Huang, H. The derivatization and antitumor mechanisms of polysaccharides. Future Med Chem. 9, 1931-1938 (2017).

35. Liu, Y., Sun, Y. \& Huang, G. Preparation and antioxidant activities of important traditional plant polysaccharides. Int J Biol Macromol. 111, 780-786 (2018).

\section{Acknowledgements}

This NF-Kappa B mechanism was obtained from KEGG pathway database by Kanehisa laboratories.

\section{Author contributions}

This project and examined sample were prepared by Wu, Y.-S. and Wu, T.-M. Cellular experiment and data analysis were performed by Wu, Y.-S., Wu, T.-M. and Nan F.-H. Discussion of the extracted polysaccharide was performed by Wu, Y.-S., Chen, K.-C. and Nan F.-H. RNA-seq and real-time PCR and data presentation were performed by $\mathrm{Wu}, \mathrm{T}$.-M. This manuscript was written by Wu, Y.-S. and Wu, T.-M. All of the authors have reviewed this manuscript and agreed to publish.

\section{Competing interests}

The authors declare no competing interests.

\section{Additional information}

Supplementary information is available for this paper at https://doi.org/10.1038/s41598-019-56246-9.

Correspondence and requests for materials should be addressed to Y.-S.W.

Reprints and permissions information is available at www.nature.com/reprints. 
Publisher's note Springer Nature remains neutral with regard to jurisdictional claims in published maps and institutional affiliations.

(c) (i) Open Access This article is licensed under a Creative Commons Attribution 4.0 International License, which permits use, sharing, adaptation, distribution and reproduction in any medium or format, as long as you give appropriate credit to the original author(s) and the source, provide a link to the Creative Commons license, and indicate if changes were made. The images or other third party material in this article are included in the article's Creative Commons license, unless indicated otherwise in a credit line to the material. If material is not included in the article's Creative Commons license and your intended use is not permitted by statutory regulation or exceeds the permitted use, you will need to obtain permission directly from the copyright holder. To view a copy of this license, visit http://creativecommons.org/licenses/by/4.0/.

(c) The Author(s) 2019 